\title{
Pengaruh Pendidikan Kesehatan Remaja Melalui Media Video Terhadap Pengetahuan Siswa Tentang Dampak Seks Bebas
}

\author{
Chelsea Titis Mentari Siwi ${ }^{1}$, J. Nugrahaningtyas W. Utami ${ }^{2}$, Tutik Astuti ${ }^{3}$ \\ ${ }^{I}$ Prodi DIV Bidan Pendidik, Universitas Respati Yogyakarta, Sleman, Yogyakarta,Daerah Istimewa Yogyakarta 55282, \\ Indonesia \\ ${ }^{2}$ Prodi DIII Fisiotherapi, Universitas Respati Yogyakarta, Sleman, Yogyakarta,Daerah Istimewa Yogyakarta 55282, \\ Indonesia \\ ${ }^{3}$ Prodi S1 Pendidikan Profesi Bidan, Universitas Respati Yogyakarta, Yogyakarta,Daerah Istimewa Yogyakarta 55282, \\ Indonesia
}

\begin{tabular}{l}
\hline ARTICLE INFORMATION \\
\hline Article Trace \\
Submission: June, 02, 2019 \\
Final Revision: September 10, 2019 \\
Available online: October, 2019 \\
\hline
\end{tabular}

Kata kunci :

Pengetahuan, video, remaja, seks bebas

Key Word:

Knowledge, Video, Adolescents, Impacts of unsafe sex

\section{Contact:}

ninnanku@gmail.com

\begin{abstract}
A B S T R A K
Saat ini, banyak remaja dihadapkan dengan berbagai tantangan yang berkaitan dengan seksualitas, seperti kasus peningkatan kehamilan remaja, dan tingginya tingkat penyakit menular seksual (IMS) seperti HIV/AIDS. Hal ini sulit dihindari remaja karena beberapa faktor, antara lain karena masa perkembangan anak yang mencari identitas diri dan selalu ingin mencoba hal baru yang ada di lingkunganya. Tujuan penelitian ini adalah ntuk mengetahui pengaruh pendidikan kesehatan remaja melalui media video terhadap perubahan pengetahuan siswa tentang dampak seks bebas usia remaja di salah satu sekolah menengah atas di Jogyakarta. Jenis penelitian ini adalah pra-eksperimen dengan rancangan penelitian one group pretest postest. Jumlah responden sebanyak 97 siswa dengan menggunakan teknik total sampling. Analisis Bivariat engan uji statistik Wilcoxon, dengan tingkat kesalahan $5 \%$ $(0,05)$. Sebagian besar pengetahuan responden pre test $69(71,1 \%)$, dan post test $61(92,4 \%)$. Rata-rata tingkat pengetahuan responden pre test mean $=77,53$ dan tingkat pengetahuan responden post test mean $=89,77$ dengan nilai signifikansi variabel pengetahuan 0,000 ( $\mathrm{P}$ value $<0,05$ ) $(\alpha)$.Ada pengaruh pendidikan kesehatan memalui media video terhadap pengetahuan siswa tentang dampak seks bebas usia remaja.
\end{abstract}

\begin{abstract}
A B S T R A C T
Nowadays, many teenagers are faced with various challenges related to sexuality, such as the case of adolescent pregnancy enhancement, and high levels of sexually transmitted diseases (IMS) such as HIV/AIDS. This is hard for the teenagers to avoid because of several factors, such as the development of a child who is looking for a personal identity and always wants to try new things in their environment. The purpose of this research is to know the influence of adolescents ' health education through video media to change students ' knowledge of adolescent free sex impact in one of the high schools in Jogyakarta. This type of research is pre-experimented with a research plan of one group Pretests postest. The number of respondents was 97 students using total sampling technique. Bivariate analysis of the statistics of Wilcoxon, with an error rate of $5 \%(0.05)$. Most of the knowledge of respondents was pre Test $69(71.1 \%)$, and post Test $61(92.4 \%)$. The average level of knowledge of respondents pre test mean $=77.53$ and the knowledge level respondent post test mean $=89.77$ with the significance value of knowledge variable $0.000(\mathrm{P}$ value $<0.05)(\alpha)$. There is a health education influence through video media to student knowledge about the impact of adolescent free sex age.
\end{abstract}




\section{PENDAHULUAN}

Saat ini, banyak remaja dihadapkan dengan berbagai tantangan yang berkaitan dengan seksualitas, seperti kasus peningkatan kehamilan remaja, dan tingginya tingkat penyakit menular seksual (IMS) seperti HIV/AIDS. (Carmichael, M., Kate, A., \& Karpicke, J. 2017). Setiap tahun diperkirakan 21 juta anak perempuan berusia 15 hingga 19 tahun mengalami kehamilan dini, pada tahun 2016 terdapat sekitar 38 juta remaja yang aktif melakukan hubungan seksual, pada negara berkembang seperti Afrika terdapat 8.900 dan di Asia terdapat kasus kehamilan remaja 8.300 per 1.000 wanita (Darroch, J., Woog, V., Bankole, A., \& Ashford, L., 2016).

IMS dan HIV/AIDS memiliki dampak besar pada kesehatan seksual dan reproduksi diseluruh dunia. Dampak yang terjadi karena IMS dan HIV/AIDS antara lain infeksi pada alat reproduksi seperti proktitis, faringitis, servisitis, vaginitis, bahkan dapat terjadi kanker serviks, abortus, kelahiran prematur, dan berat badan lahir rendah. Dampak tersebut juga dapat terjadi pada neonatus akibat penularan dari ibu ke bayi, antara lain konjungtivitis, kebutaan, pneumonia, dan bayi lahir mati Depkes RI. (2015). Menurut WHO tahun 2018, dilaporkan bahwa setiap tahun didunia, diperkirakan terdapat 357 kasus IMS, diantaranya klamidia (131 juta kasus), gonore (78 juta kasus), sifilis (5,6 juta kasus), trikomoniasis (143 juta kasus), HPV (290 juta kasus), dan herpes (500 juta kasus. Dilansir oleh WHO tahun 2015 terkait situasi Indonesia didapatkan data sebesar $5,26 \%$ pelajar di Indonesia pernah melakukan hubungan intim seperti suami istri. Presentase pelajar laki-laki lebih banyak mengaku telah melakukan hubungan intim seperti suami istri

Pendidikan kesehatan merupakan salah satu upaya dalam mencegah remaja berperilaku tidak sehat, pendidikan kesehatan perlu diberikan agar remaja mengetahui informasi-informasi penting tentang bahaya kesehatan yang mengancam mereka. Pendidikan kesehatan yang perlu disampaikan kepada remaja di sekolah harus bersifat promotif dan preventif. Pendidikan kesehatan (health education), pada prinsipnya bertujuan agar masyarakat berperilaku sesuai dengan nilai-nilai kesehatan (Notoatmodjo, 2010)

Video merupakan media yang secara efektif dapat meningkatkan pemahaman dan meningkatkan belajar pada seseorang. Video banyak memberikan manfaat besar bagi guru dan peserta didik, untuk merangsang kinerja yang lebih dalam banyak konteks, dan mempengaruhi motivasi, kepercayaan, dan sikap siswa secara positif (Schneps, M. H., Griswold, A., Finkelstein, N., McLeod, M., \& Schrag, D. P., 2010)

Studi pendahuluan yang dilakukan di salah satu sekolah Yogyakarta tahun 2018, didapatkan data bahwa berdasarkan hasil wawancara kepada 10 siswa didapatkan hasil bahwa 10 siswa-siswi tersebut belum pernah mendapatkan penyuluhan tentang bahaya aktivitas seks diusia remaja, 10 orang mengatakan tidak mendapatkan pelajaran tentang bahaya aktivitas seks bebas, 4 orang mengatakan tidak tahu tentang penyakit menular seksual, baik itu penyebab dan akibat dari penyakit menular seksual, dan 3 orang mengatakan bahwa mengetahui tentang penyakit menular seksual dari internet dan televisi.

Berdasarkan hasil studi pendahuluan tersebut, peneliti tertarik untuk meneliti dengan judul "Pengaruh Pendidikan Kesehatan Remaja melalui Media Video terhadap Pengetahuan Siswa tentang Dampak Seks Bebas Usia Remaja pada salah satu sekolah menengah atas di Yogyakarta.

\section{METODE PENELITIAN}

Penelitian ini merupakan penelitian praeksperimen dengan rancangan penelitian one group pretest postest. Rancangan ini tidak memakai kelompok pembanding (kontrol), tetapi sudah dilakukan observasi pertama (pretest) yang memungkinkan menguji perubahanperubahan yang terjadi setelah adanya 
eksperimen (program). Penelitian dilakukan dengan jumlah sampel sebanyak 97 responden. Teknik pengambilan sampel menggunakan total sampling. Uji bivariate dalam penelitian ini menggunakan uji Wilcoxon.

\section{HASIL DAN PEMBAHASAN}

\section{a) Karakteristik Responden}

Tabel 1. Distribusi Frekuensi Karakteristik Responden

\begin{tabular}{lll}
\hline Karakteristik & n & \% \\
\hline Jenis Kelamin & & \\
Perempuan & 51 & 52,6 \\
Laki-laki & 46 & 47,4 \\
Total & $\mathbf{9 7}$ & $\mathbf{1 0 0}$ \\
\hline Umur & & \\
15 tahun & 38 & 39,2 \\
16 tahun & 54 & 55,7 \\
17 tahun & 5 & 5,2 \\
Total & $\mathbf{9 7}$ & $\mathbf{1 0 0}$ \\
\hline
\end{tabular}

Berdasarkan tabel 1 diketahui bahwa sebagian besar responden penelitian berjenis kelamin perempuan 51 responden (52,6\%). Diketahui umur responden paling banyak adalah umur 16 tahun berjumlah 54 responden $(55,7 \%)$. Hal ini menunjukkan bahwa remaja sangat rentan terhadap masalah kesehatan. Remaja saat ini beresiko melakukan seks bebas, pemicunya karena lingkungan, sosial budaya, penghayatan, keagamaan, penerapan nilai-nilai faktor psikologis dan ekonomi. Secara garis besar faktor yang berpengaruh terhadap perilaku seks remaja terdiri dari faktor internal (usia, sikap permisif, dan gender) dan eksternal (lingkungan, sosial budaya, dan penyalahgunaan teknologi informasi (Sarwono, S, W.,2013).

Pada penelitian ini responden yang menjadi partisipan merupakan remaja tengah yang berumur 15-17 tahun dan menunjukkan karakteristik usia responden berada pada rentang 15-16 tahun (94,8\%), dan merupakan masa peralihan dari anak-anak untuk menuju remaja akhir (Dewi, H, E., 2012).

\section{b) Pengetahuan remaja sebelum dan sesudah pendidikan kesehatan}

Tabel 2. Distribusi Frekuensi Pengetahuan

Remaja Tentang Dampak Seks Bebas usia

Remaja Sebelum dan Setelah Pendidikan

Kesehatan

\begin{tabular}{lllll}
\hline $\begin{array}{c}\text { Kategori } \\
\text { Pengetahuan }\end{array}$ & & Pre & \multicolumn{2}{c}{ Post } \\
\hline Kurang & n & \% & n & \% \\
Cukup & 7 & 7,2 & 0 & 0 \\
Baik & 21 & 21,6 & 5 & 5,2 \\
Total & 69 & 71,1 & 92 & 94,8 \\
\hline
\end{tabular}

Berdasarkan tabel 2 dapat dilihat bahwa pengetahuan sebelum pendidikan kesehatan untuk kategori baik ada 69 responden $(71,1 \%)$ dan setelah diberikan pendidikan kesehatan menjadi 92 responden $(94,8 \%)$. Hasil ini menujukkan bahwa pengetahuan responden penelitian belum sepenuhnya tahu tentang dampak seks bebas usia remaja, maka responden membutuhkan proses pembelajaran agar pengetahuan mereka semakin luas. Sehingga pengetahuan merupakan hasil "tahu" dan ini terjadi setelah orang mengadakan pengindraan terhadap suatu objek tertentu (Wawan, A., \& Dewi, M., 2011).

c) Nilai rata-rata pengetahuan remaja sebelum dan sesudah pendidikan kesehatan.

Tabel 3. Rata-rata Pengetahuan Remaja Tentang Dampak Seks Bebas Usia Remaja Sebelum dan Sesudah Pendidikan Kesehatan

\begin{tabular}{cc}
\hline Pengetahuan & Mean \\
\hline Pre Test & 77,53 \\
Post Test & 89,77 \\
\hline
\end{tabular}

Berdasarkan tabel 3 diketahui bahwa rata-rata pengetahuan sebelum pendidikan kesehatan melalui media video sebesar 77,53 dan setelah pendidikan melalui media video terjadi peningkatan rata-rata pengetahuan yaitu 89,77. Diketahui selisih rata-rata pengetahuan setelah pendidikan kesehatan dan setelah pendidikan 
kesehatan yaitu 12,24. Hasil tersebut menunjukkan perubahan pengetahuan remaja yang meningkat setelah peneliti memberikan pendidikan kesehatan tentang dampak seks bebas usia remaja secara langsung melalui media video. Sesuai dengan pendapat Wahit Iqbal M, Chayatin Nurul, Rozikin Khoirul, Apriadi., 2009) tentang pendidikan kesehatan yang bertujuan agar masyarakat dapat memutuskan kegiatan yang paling tepat guna untuk meningkatkan taraf hidup sehat dan kesejahteraan masyarakat.

\section{d) Pengetahuan sebelum dan sesudah pendidikan kesehatan}

Tabel 4. Perubahan Pengetahuan Remaja Tentang Dampak Seks Bebas Usia Remaja Sebelum dan Sesudah Pendidikan Kesehatan

\begin{tabular}{cc}
\hline Pengetahuan & P value \\
\hline Pre-Post Test & 0,000 \\
\hline
\end{tabular}

Hasil analisis stastistik (uji wilcoxon) dengan membandingkan rata-rata nilai pengetahuan pretest dan post-test didapatkan hasil bahwa terjadi peningkatan nilai pengetahuan dengan nilai signifikan yang bermakna secara uji statistik yaitu sig (2-Tailed) 0,000 ( $P$ value $<0,05)$. Hasil penelitian ini sesuai dengan penelitian yang dilakukan oleh Kurniasari (2017) dengan judul "Pengaruh Media Video Terhadap Pengetahuan Dalam Pencegahan Perilaku Seks Pranikah Siswa SMP”. Hasil penelitian yang dilakukan Kurniasari adalah nilai signifikansi $\mathrm{P}$ value $=$ $0,025 \quad(p<0,05)$. Terdapat pengaruh antara sebelum perlakuan penayangan video mengenai kesehatan reproduksi dengan sesudah perlakuan penayangan video kesehatan reproduksi dan bahaya seks pranikah.

\section{KESIMPULAN}

1. Pengetahuan remaja sebelum diberikan pendidikan kesehatan melalui media video tentang dampak seks bebas usia remaja didapatkan bahwa sebagian besar kategori pengetahuan baik sebesar $71,1 \%$.
2. Ada perubahan pengetahuan responden setelah diberikan pendidikan kesehatan tentang dampak seks bebas usia remaja yaitu mayoritas pengetahuan baik sebesar $94,8 \%$.

3. Terdapat pengaruh yang bermakna antara pendidikan kesehatan remaja melalui media video tentang dampak seks bebas usia remaja terhadap perubahan pengetahuan dengan $\mathrm{p}$ value $=0,000<0,05(\alpha)$.

\section{DAFTAR PUSTAKA}

Carmichael, M., Kate, A., \& Karpicke, J. (2017). Internet. Assessing the Impact of Educational Video on Student Engagement, Critical Thingking and Learning : The Current of Play. https://us.sagepub.com/sites/default/files/h evideolearning.pdf. Diakses pada 14 November 2018.

Darroch, J., Woog, V., Bankole, A., \& Ashford, L. (2016). Adding it Up : Costs and Benefits of Meeting the Contraceptive Needs of Adolescents. https://www.guttmacher.org/sites/default/f iles/report_pdf/adding-it-up-adolescentsreport.pdf. Diakses pada 15 November 2018.

Depkes RI. (2015). Pedoman Naisonal Penanganan Inkesi Menular Seksual. http://siha.depkes.go.id/portal/files_upload /Pedoman Nasional Tatalaksana IMS 20 15.pdf Diakses pada 12 November $201 \overline{8}$

Dewi, H, E. (2012). Memahami Perkembangan Fisik Remaja. Yogyakarta : Gosyen Publishing.

Notoatmodjo, S. (2010). Promosi Kesehatan teori dan aplikasi. Jakarta. Rineka Cipta.

Schneps, M. H., Griswold, A., Finkelstein, N., McLeod, M., \& Schrag, D. P. (2010). Using video to build learning contexts online. Science, 328(5982), 1119-1120. https://doi.org/10.1126/science.1186934.

Sarwono, S, W. (2013). Psikologi Remaja Edisi Revisi. Jakarta : Raja Grafindo Persada. 
Wahit Iqbal M, Chayatin Nurul, Rozikin Khoirul, Apriadi. (2009), Promosi Kesehatan. Sebuah Pengantar Proses Belajar Mengajar Dalam Pendidikan. Graha Ilmu : Yogyakarta.

Wawan, A., \& Dewi, M. (2011). Teori dan Pengukuran, Pengetahuan, Sikap, Dan Perilaku Manusia. Nuha Medika. Yogyakarta.
WHO. (2018). Adolescent Pregnancy : Issues in Adolescent Health and Development. Geneva. http://www.who.int/newsroom/fact-sheets/detail/adolescentpregnancy. Diakses pada 15 November 2018

WHO. (2015). Perilaku Beresiko Kesehatan Pelajar SMP dan SMA Di Indonesia. http://www.who.int/ncds/surveillance/gshs /GSHS_2015_Indonesia_Report_Bahasa.p df. Diakses pada 12 November 2018. 